\title{
Strategies for noise reduction and standardization of milk mid-infrared spectra from dairy cattle
}

\author{
K. M. Tiplady, ${ }^{1,2 *}$ R. G. Sherlock, ${ }^{1}$ M. D. Littlejohn,,${ }^{1,2}$ J. E. Pryce,,${ }^{3,4}$ S. R. Davis, ${ }^{1}$ D. J. Garrick, ${ }^{2}$ R. J. Spelman, ${ }^{1}$ \\ and B. L. Harris ${ }^{1}$ \\ ${ }^{1}$ Research and Development, Livestock Improvement Corporation, Private Bag 3016, Hamilton 3240, New Zealand \\ ${ }^{2}$ School of Agriculture, Massey University, Ruakura, Hamilton 3240, New Zealand \\ ${ }^{3}$ Agriculture Victoria, AgriBio, Centre for AgriBioscience, Bundoora, VIC 3083, Australia \\ ${ }^{4}$ School of Applied Systems Biology, La Trobe University, Bundoora, VIC 3083, Australia
}

\section{ABSTRACT}

The use of Fourier-transform mid-infrared (FTIR) spectroscopy is of interest to the dairy industry worldwide for predicting milk composition and other novel traits that are difficult or expensive to measure directly. Although there are many valuable applications for FTIR spectra, noise from differences in spectral responses between instruments is problematic because it reduces prediction accuracy if ignored. The purpose of this study was to develop strategies to reduce the impact of noise and to compare methods for standardizing FTIR spectra in order to reduce between-instrument variability in multiple-instrument networks. Noise levels in bands of the infrared spectrum caused by the water content of milk were characterized, and a method for identifying and removing outliers was developed. Two standardization methods were assessed and compared: piecewise direct standardization (PDS), which related spectra on a primary instrument to spectra on 5 other (secondary) instruments using identical milkbased reference samples $(\mathrm{n}=918)$ analyzed across the 6 instruments; and retroactive percentile standardization (RPS), whereby percentiles of observed spectra from routine milk test samples $(\mathrm{n}=2,044,094)$ were used to map and exploit primary- and secondaryinstrument relationships. Different applications of each method were studied to determine the optimal way to implement each method across time. Industry-standard predictions of milk components from 2,044,094 spectra records were regressed against predictions from spectra before and after standardization using PDS or RPS. The PDS approach resulted in an overall decrease in root mean square error between industry-standard predictions and predictions from spectra from 0.190 to $0.071 \mathrm{~g} / 100 \mathrm{~mL}$ for fat, from 0.129 to $0.055 \mathrm{~g} / 100$

Received December 10, 2018.

Accepted March 4, 2019.

*Corresponding author: Kathryn.Sanders@lic.co.nz
$\mathrm{mL}$ for protein, and from 0.143 to $0.088 \mathrm{~g} / 100 \mathrm{~mL}$ for lactose. Reductions in prediction error for RPS were similar but less consistent than those for PDS across time, but similar reductions were achieved when PDS coefficients were updated monthly and separate primary instruments were assigned for the North and South Islands of New Zealand. We demonstrated that the PDS approach is the most consistent method to reduce prediction errors across time. We also showed that the RPS approach is sensitive to shifts in milk composition but can be used to reduce prediction errors, provided that secondary-instrument spectra are standardized to a primary instrument with samples of broadly equivalent milk composition. Appropriate implementation of either of these approaches will improve the quality of predictions based on FTIR spectra for various downstream applications.

Key words: Fourier-transform mid-infrared spectra, standardization, trait prediction, milk composition, dairy cattle

\section{INTRODUCTION}

Fourier-transform infrared spectroscopy is a method to determine light absorbance at wavenumbers across the infrared spectrum. Applications using Fouriertransform infrared data from the mid-infrared range have increased in popularity over the last decade for predicting milk composition and other novel traits. De Marchi et al. (2014) comprehensively reviewed the use of Fourier-transform mid-infrared (FTIR) spectroscopy and many potential applications for the use of the resulting spectra as a phenotyping tool. Ongoing research includes studies of individual milk proteins and fatty acids (Lopez-Villalobos et al., 2014; McDermott et al., 2016; Bonfatti et al., 2017b) and technological properties (Cecchinato et al., 2015; Toffanin et al., 2015; Visentin et al., 2015). Studies have predicted indirect traits related to pregnancy (Lainé et al., 2017; ToledoAlvarado et al., 2018a,b), energy status (McParland 
et al., 2015; Grelet et al., 2016; Mehtiö et al., 2018), efficiency (McParland and Berry, 2016; Shetty et al., 2017), and methane emissions (Vanlierde et al., 2013, 2015; Bittante and Cipolat-Gotet, 2018).

Although FTIR spectra have many valuable applications, the ability to predict traits directly from the spectra and to transfer calibration equations between instruments is hindered by several sources of noise. These sources include noise across bands of the infrared spectrum due to the water content of milk and noise resulting from spectral outliers caused by sample or instrument anomalies. A third source of noise is the variation between instruments or within instruments across time. This variation, which exists even between instruments of the same brand, can result in prediction errors and bias and is particularly problematic when applying calibration models developed on one instrument across a historical database of spectra collected on different instruments (Grelet et al., 2015; Bonfatti et al., 2017a).

A widely used practice to address the issue of variation between instruments and shifts in instruments across time is to adjust trait predictions by instrument correction coefficients, previously evaluated from the analysis of reference samples, using the approach outlined by Lynch et al. (2006). However, that method is only applicable when reference samples are available for a trait. With the growing number of traits predicted from spectra, many of which do not have reference samples, there is increased interest in standardizing individual FTIR spectra wavenumbers directly (Grelet et al., 2015, 2017; Bonfatti et al., 2017a). Recent publications by Grelet et al. (2015) and Bonfatti et al. (2017a) present methods for standardizing individual wavenumber absorbance values. Both strategies involve assigning a primary instrument and standardizing spectra from other (secondary) instruments to align them to the spectral response of the primary instrument. Grelet et al. (2015) presented a piecewise direct standardization (PDS) approach based on the method described by Wang et al. (1991). Bonfatti et al. (2017a) presented a retroactive approach (retroactive percentile standardization, RPS), in which percentiles of spectral responses for each wavenumber are used to map the relationships between primary and secondary instruments.

The effectiveness of standardization for reducing prediction errors when transferring calibration models between instruments for fat composition traits has been demonstrated previously (Grelet et al., 2015; Bonfatti et al., 2017a). Grelet et al. (2017) also demonstrated the effectiveness of standardization for reducing prediction errors for traits with lower quality calibration models such as methane emissions and cheese yield.
Although those studies demonstrate the clear benefits of standardization, to date no studies have directly compared the reduction in prediction errors for the 2 methods when measured across the same data set.

The purpose of this study was to develop strategies to reduce the impact of noise on predictions and to compare methods for standardizing FTIR spectra from milk samples collected across multiple-instrument networks. Our aims included identifying bands with high noise levels across the mid-infrared spectrum, developing an outlier removal method, and quantifying the effect of standardization on milk trait predictions. Standardization methods were compared across the same set of milk samples using industry-standard trait predictions for concentrations of major milk components, and different applications of each method were studied to determine the optimal way to implement each method across time.

\section{MATERIALS AND METHODS}

\section{Ethics Statement}

All data were generated as part of routine commercial activities and were outside the scope of requiring formal ethics approval.

\section{Instrumentation}

Fourier-transform mid-infrared spectra from 6 Bentley FTS spectrometers (Bentley Instruments, Chaska, $\mathrm{MN}$ ), located at 2 different centers in New Zealand within the Livestock Improvement Corporation (LIC) milk-testing network, were used in this study. Three instruments (A4 to A6) were located in Hamilton (North Island) and 3 instruments (A1 to A3) were located in Christchurch (South Island). Each spectral record had absorbance values reported for 899 wavenumbers across the range from 649.03 to $3,998.59 \mathrm{~cm}^{-1}$. This range is referred to broadly as the "mid-infrared region" throughout this study. However, subdivisions of the infrared region vary across different sources, sometimes defining the range 649.03 to $3,998.59 \mathrm{~cm}^{-1}$ as including part of the long-wavelength infrared and short-wavelength infrared regions (Bittante and Cecchinato, 2013).

\section{Milk-Based Reference Samples}

Milk-based reference sample sets were used to calibrate instruments weekly to meet International Committee for Animal Recording (ICAR) requirements, in accordance with relevant standards (ISO 9622:2013; ISO, 2013). Reference sample calibration sets were prepared by MilkTestNZ (Hamilton, New Zealand) to 
comply with ICAR guidelines (ICAR, 2017). Those sets included up to 11 milk-based samples with known concentrations of fat, protein, and lactose, as determined by industry-accepted chemical reference methods, in accordance with relevant standards (ISO 1211:2010, ISO, 2010; ISO 22662:2007, ISO, 2007; ISO 89684:2016, ISO, 2016). A separate set of samples, designed to be identical in composition, was generated for each instrument, with samples in each set reflecting milk component concentrations ranging from $\sim 0.1$ to 6.1 $\mathrm{g} / 100 \mathrm{~mL}$ for fat, $\sim 3.5$ to $4.5 \mathrm{~g} / 100 \mathrm{~mL}$ for protein and $\sim 4.7$ to $5 \mathrm{~g} / 100 \mathrm{~mL}$ for lactose.

In total, 918 milk-based samples from reference sets across 16 wk from February to May 2018 were included in this study. In each week, there were 6 sets of samples, designed to be identical, with each set analyzed across a different instrument (A1 to A6). On average, spectra from only 9.6 of the 11 samples were available for each week. This was because some reference sets included only 10 samples (instead of 11), and because some spectra records were discarded if samples were processed out of sequence during the calibration process.

\section{Noise Region Identification Using Reference Samples}

Noise regions across the mid-infrared spectral range were identified using spectra generated from the weekly instrument calibration process. During instrument calibration, each reference sample was analyzed in duplicate to obtain 2 spectra records (paired spectra), which were averaged. For each set of paired spectra $(n=918)$, the difference in absorbance was calculated for each wavenumber. Paired spectra represented the same reference sample analyzed in duplicate on the same instrument, so the expectation was that the absorbance difference would be zero, under the assumption that there was no other interference in the absorbance signal. Metrics to describe the distribution of absorbance differences for each wavenumber were calculated as follows: the mean of the absolute differences for a wavenumber; the standard deviation of the differences for a wavenumber; and the Wasserstein distance metric, to compare the distribution of differences for a wavenumber to the distribution of differences for the wavenumber with the lowest variance. Wasserstein distance metrics were calculated using the transport package in $\mathrm{R}$ (Schuhmacher et al., 2017).

Paired-spectra difference metrics were multiplied by 100 and the distributions of each of the scaled absolute mean, the scaled standard deviation, and the scaled Wasserstein distance were approximated with a Cauchy distribution. Location and scale parameters for each fitted Cauchy distribution were estimated using the fitdistrplus package in R (Delignette-Muller and Dutang, 2015), where the location parameter defined the location of the distribution peak, and the scale parameter defined the spread of the distribution. Critical-value thresholds based on these parameters were evaluated for each scaled metric for each of the $\alpha$-levels 0.05, 0.1 , and 0.15. A wavenumber was assigned to belong to a noise region if the scaled metric was above the corresponding critical-value threshold for a specified $\alpha$-level. Levels of $\alpha$ indicated the probability of falsely assigning a wavenumber to a noise region, with higher $\alpha$-levels resulting in an increased likelihood of assigning wavenumbers to noise regions.

\section{Identification of a Primary Instrument}

Averaged spectra from milk-based reference samples ( $\mathrm{n}=918)$ were used to identify a high-performing primary instrument to which the other secondary instruments would be calibrated. For each sample, uncorrected predictions of milk component concentrations were generated by applying industry-accepted calibration equations to the average of FTIR wavenumber absorbance values. The intercept, slope, coefficient of determination $\left(\mathrm{R}^{2}\right)$, root mean square error (RMSE), and relative RMSE between uncorrected predictions of milk component concentrations and concentrations determined by chemical reference methods were calculated. Relative RMSE values were calculated as the ratio of the RMSE to the overall average of the reference values for each milk component. The instrument with the highest average $\mathrm{R}^{2}$ across milk component concentrations for fat, protein, and lactose was designated as the primary instrument (A6). The primary instrument also demonstrated consistently lower relative RMSE values and lower deviations from unity for the slope across all 3 milk components, compared with all other instruments.

\section{Milk Test Samples from Routine Milk Testing}

In New Zealand, milk testing is currently carried out on $\sim 3$ million cows per year, located in $\sim 7,500$ herds (LIC and DairyNZ, 2017). Most dairy herds in New Zealand operate as pasture-based, seasonal production systems, with milk testing conducted on a two-monthly basis so that each cow has 3 to 4 tests per lactation. LIC is 1 of 2 milk-testing providers in New Zealand and has both Foss (Hillerød, Denmark) and Bentley instruments in their milk-testing network. Samples from the North Island were processed at the Hamilton center and samples from the South Island were processed at the 
Christchurch center. Samples were randomly allocated to instruments at each center, with approximately half being analyzed on Bentley instruments.

Fourier-transform mid-infrared spectra records from 2,109,750 individual milk test samples for 1,533,669 cows across 5,574 herds were included in the data set. Samples were collected and analyzed on Bentley instruments as part of routine milk testing conducted by LIC over the period from September 2017 to May 2018. Median calving dates were August 8, 2017, for cows with samples in the North Island and August 20, 2017, for cows with samples in the South Island. The median parity of cows was 3 , with a range of 1 to 15 . Cows were from a mixed-breed population. The breed composition of cows sampled comprised 516,893 Holstein-Friesian, 159,249 Jersey, 762,210 Holstein-Friesian $\times$ Jersey, and 95,317 other breeds.

\section{Outlier Removal for Milk Test Samples}

The squared Mahalanobis distance (MD) between industry-standard predictions of milk component concentrations (fat, protein, and lactose) were evaluated for each milk test record. Outliers were identified and removed if the MD of milk component predictions had a $P$-value $<0.001$ based on a $\chi^{2}$ distribution with 3 degrees of freedom (df).

The MD between each spectrum and the average spectra were evaluated after excluding noise regions. Under the assumption that the spectra were distributed as a multivariate normal distribution, the MD values for the spectra were expected to follow a $\chi^{2}$ distribution with $r$ degrees of freedom, where $r$ is the number of wavenumbers after excluding noise regions. Instrumentspecific clustering was present in the MD values, necessitating the calculation of within-instrument MD values for the purpose of outlier removal.

The distribution of best fit was determined for each set of within-instrument MD values using the fitdistrplus package in $\mathrm{R}$ (Delignette-Muller and Dutang, 2015). The distributions considered were the normal, gamma, $\chi^{2}$, lognormal, and logistic distribution. The logistic distribution was identified as the best fit to within-instrument MD values, based on having the lowest average information criterion (AIC), on average, across instruments. Outliers were identified and removed if the within-instrument MD had a $P$-value $<$ 0.001 based on the logistic distribution of best fit.

\section{Evaluation of Standardization Coefficients}

Piecewise Direct Standardization. Coefficient sets to relate primary-instrument spectra to spectra from secondary instruments were generated using a PDS approach (Grelet et al., 2015). Briefly, milk-based reference samples measured across all instruments were used to relate the response for each wavenumber $j$ on the primary instrument to a small window around the same wavenumber on each secondary instrument. Each secondary instrument window included 5 responses, centered on the wavenumber $j$. A principal components regression was used to map the relationship between the primary-instrument spectral wavenumber and each corresponding secondary-instrument spectral window:

$$
\mathbf{p}_{j}=\boldsymbol{\beta}_{0 j}+\mathbf{S}_{j} \boldsymbol{\beta}_{j},
$$

where $\mathbf{p}_{j}$ is a vector of average absorbance values from paired spectra for up to 153 samples for the $j$ th wavenumber on the primary instrument; $\mathbf{S}_{j}=\left[s_{j-2}, s_{j-1}, s_{j}, s_{j+1}, s_{j+2}\right]$ is a matrix of the corresponding window on the secondary instrument; $\boldsymbol{\beta}_{0 j}$ is an offset term; and $\boldsymbol{\beta}_{j}$ is a vector representing transformation coefficients. These defined a complete standardization coefficient set comprising PDS estimates of $\boldsymbol{\beta}_{0 j}$ and $\boldsymbol{\beta}_{j}$ for wavenumbers $j=3$ to $j=897$ (895 wavenumbers), with coefficient sets for $j=1, j=2, j=898$, and $j=$ 899 being undefined.

Five time-based criteria were used to restrict the samples included for evaluating coefficient sets. An overall coefficient set was evaluated based on all samples (PDS:Overall). For each of $k=1$ to $16 \mathrm{wk}$, coefficient sets were evaluated: using samples in week $k$ only (PDS:Weekly), using samples from all other weeks, except week $k$ (PDS:AllOtherWks); using samples from all weeks in the same calendar month as week $k$, but excluding week $k$ (PDS:Monthly); and using the last $w$ weeks of samples before week $k$, where $w=1$ to 8 (PDS:RollingWks). These coefficient sets allowed different applications of the PDS method across time, and defined different values for $\mathbf{p}_{j}$ and $\mathbf{S}_{j}$ in equation [1].

Retroactive Percentile Standardization. Coefficient sets to relate primary-instrument spectra to spectra from secondary instruments were assessed using the RPS approach outlined by Bonfatti et al. (2017a). Briefly, standardization coefficients were calculated using linear regression to map the absorbance percentiles for each wavenumber from the primary instrument to the corresponding absorbance percentiles from each secondary instrument.

Three separate RPS coefficient sets were constructed from milk test samples: using spectra from all milk test samples to evaluate an overall coefficient set (RPS: Overall); using spectra from milk test samples in each month to evaluate monthly coefficient sets (RPS: 
Monthly); and using spectra from milk test samples in each month, with a different primary instrument used for spectra from South Island samples, to evaluate coefficient sets for each island in each month (RPS: Monthly ${ }^{\text {Is }}$. To evaluate the RPS:Monthly ${ }^{\text {Is }}$ coefficient sets, an alternative South Island instrument (A1) was designated as the primary instrument for standardizing South Island spectra. This instrument was selected from South Island instruments following the methodology described for designating an overall primary instrument.

\section{Assessment of Standardization Strategies}

Assessment of standardization strategies was undertaken in 2 stages: (1) assessment of PDS on spectra from milk-based reference samples; and (2) assessment of PDS and RPS on spectra from milk test samples.

Assessment of PDS on Milk-Based Reference Samples. The process for assessment of PDS strategies is shown in Figure 1. From a total of 918 milk-based reference samples, 153 were analyzed in duplicate on the primary instrument to obtain primary instrument spectra. Corresponding samples, designed to be identical, were analyzed in duplicate on the 5 secondary instruments $(\mathrm{n}=765)$ to obtain spectra for each secondary instrument. Calibration models for concentrations of fat, protein, and lactose were developed by regressing the average absorbance values from primary instrument paired spectra against component concentrations previously determined by chemical reference methods. In these models, wavenumbers from noise regions were excluded and each partial least squares regression was conducted using the plsr package in R (Mevik et al., 2018). For each model, the number of components to minimize the RMSE of prediction was identified and subsequently used in model applications.

Secondary-instrument reference sample spectra were standardized using the PDS:Weekly, PDS:AllOtherWks, PDS:Monthly, and PDS:RollingWks coefficient sets. Calibration models developed from primary-instrument spectra were then applied to primary-instrument spectra and unstandardized and standardized secondaryinstrument spectra. This resulted in a set of predicted traits from each of the primary-instrument spectra, the unstandardized secondary-instrument spectra, and each of the standardized secondary-instrument spectra data sets.

Primary-instrument trait predictions were regressed on predictions from unstandardized and standardized secondary-instrument spectra, and the $\mathrm{R}^{2}$, intercept, slope, RMSE, and relative RMSE were evaluated for each strategy. Relative RMSE values were calculated as the ratio of the RMSE to the overall average of the reference values for each milk component. Because the PDS:RollingWks strategies were dependent on having up to 8 wk of spectra from previous weeks available, coefficient sets for $w=8$ were only estimable for weeks $k=9$ to 16 . Therefore, to ensure that standardization strategies were compared across the same period, comparisons between primary- and secondary-instrument spectra were restricted to weeks $k=9$ to 16 across all strategies $(\mathrm{n}=79)$.

Assessment of PDS and RPS on Milk Test Samples. The process for assessment of PDS and RPS strategies is shown in Figure 2. Milk test samples (n $=2,044,094$ ) were analyzed on 1 of 6 instruments, and sample spectra were standardized using PDS:Overall, RPS:Overall, RPS:Monthly, and RPS:Monthly ${ }^{\text {Is }}$ coefficient sets. Industry-standard calibration equations were used to predict individual milk component concentrations (fat, protein, and lactose) from unstandardized and standardized spectra. This resulted in a set of predicted traits from unstandardized spectra and a set of predicted traits from each of the standardized sets of spectra. Traits predicted from unstandardized spectra were also adjusted by instrument-specific calibration

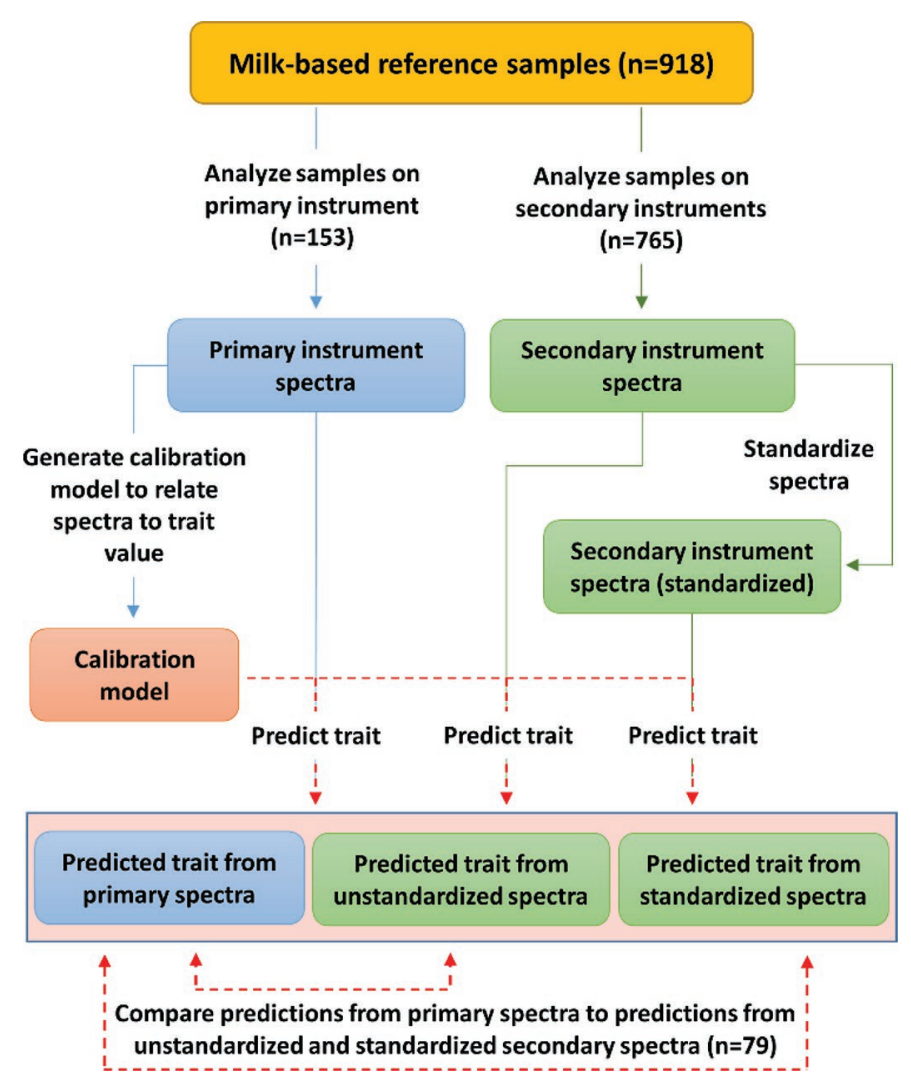

Figure 1. Summary of process for assessment of piecewise direct standardization (PDS) strategies on 79 sets of identical milk-based reference samples. 
coefficients (previously evaluated from the weekly calibration process), to obtain the industry-standard prediction for each trait, in accordance with ICAR requirements and relevant milk testing standards (ISO 9622:2013; ISO, 2013).

Industry-standard trait predictions were regressed on predictions from unstandardized and standardized spectra, and the overall $\mathrm{R}^{2}$, intercept, slope, RMSE, and relative RMSE were evaluated for each strategy. Relative RMSE values were calculated as the ratio of the RMSE to the overall average of the industrystandard prediction for each milk component. Relative RMSE values for each individual milk component were compared overall and by individual instrument and month.

\section{RESULTS AND DISCUSSION}

\section{Noise Region Identification Using Reference Samples}

Profiles of absorbance differences for paired-spectra records across the mid-infrared spectrum are presented in Figure 3. Six separate regions are identified in Figure 3a based on noise levels observed across the spectrum, with close-up views of regions (i), (iii), and (v) shown in Figures 3b, 3c, and 3d, respectively. Representative distributions of absorbance differences for individual wavenumbers from each region are presented in Figure 4. Regions of the spectrum below $\sim 950 \mathrm{~cm}^{-1}$ and from $\sim 3,000$ to $3,700 \mathrm{~cm}^{-1}$ had the largest noise levels. Notably, noise observed in the region $\sim 1,600$ to $1,700 \mathrm{~cm}^{-1}$ was much lower than that in regions (i) or (v).

Table 1 presents noise regions defined by scaled paired-spectra difference metrics. Wavenumbers were assigned to noise regions if the scaled difference metric was above the critical-value threshold from the appropriate Cauchy distribution. Location and scale parameters for Cauchy distributions were 0.0143 and 0.0157 for absolute means; 0.0170 and 0.0187 for standard deviations; and 0.00989 and 0.0163 for Wasserstein distances. For the first and second noise regions, for any given $\alpha$-level, noise region boundaries defined for each metric differed by up to only 7 wavenumbers. The third noise region was the most variable between $\alpha$-levels and between metrics, the upper limit varying between the standard deviation and Wasserstein distance metrics by 75 wavenumbers for $\alpha=0.1$ and by 150 wavenumbers for $\alpha=0.15$.

Similar noise regions have been presented in other studies: 1.616 to $1.678 \mathrm{~cm}^{-1}$ and 3,066 to $3,668 \mathrm{~cm}^{-1}$ (Soyeurt et al., 2010); 1,586 to $1,698 \mathrm{~cm}^{-1}$ and 3,052 to $3,669 \mathrm{~cm}^{-1}$ (Bittante and Cecchinato, 2013); and 1,600 to $1,689 \mathrm{~cm}^{-1}$ and 3,008 to $5,010 \mathrm{~cm}^{-1}$ (Grelet

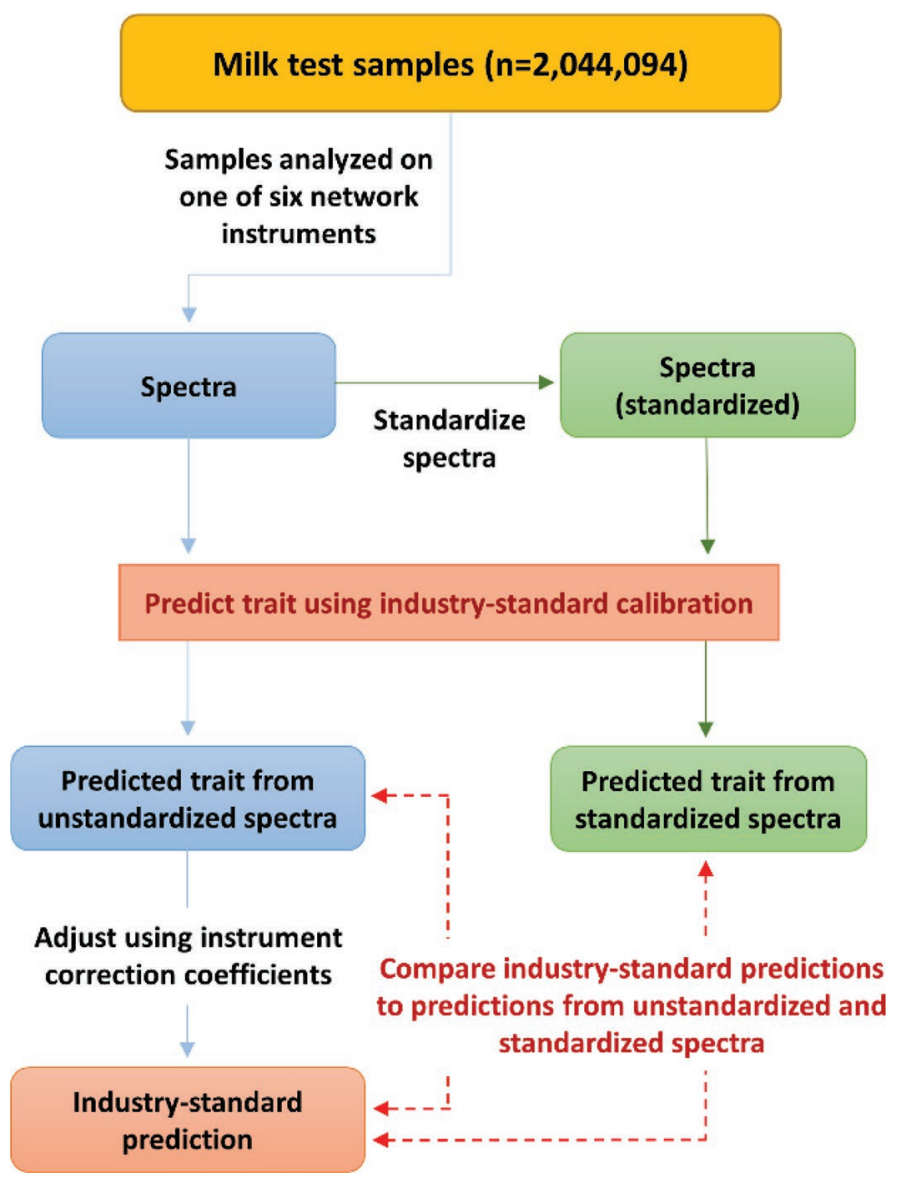

Figure 2. Summary of process for assessment of piecewise direct standardization (PDS) and retroactive percentile standardization (RPS) strategies on 2,044,094 milk test samples.

et al., 2015). Wavenumbers lower than $925 \mathrm{~cm}^{-1}$ were not reported in those studies, because they used Foss instruments (Hillerød, Denmark) that do not report any part of the spectra from this region.

In the present study, most of the region between 649.03 and $925 \mathrm{~cm}^{-1}$ had high noise levels (Figure 3). However, the first wavenumber, $649.03 \mathrm{~cm}^{-1}$, was an exception and had comparatively low noise levels with a scaled absolute difference mean of $8.92 \mathrm{e}^{-02}$ and scaled difference standard deviation of $1.28 \mathrm{e}^{-01}$. Low noise levels were also observed in the distribution of pairedspectra absorbance differences for $649.03 \mathrm{~cm}^{-1}$ (not shown), which was narrower than that for the wavenumber 1,648.7 $\mathrm{cm}^{-1}$ (Figure 4, region iii), but wider than that for 3,924 $\mathrm{cm}^{-1}$ (Figure 4, region vi). Notably, for $\alpha=0.05$, the wavenumber $649.03 \mathrm{~cm}^{-1}$ was not classified as part of the first noise region for any of the difference metrics (Table 1).

The second noise region defined in this study was in the water absorption band of the spectrum affected by O-H bending $\left(\sim 1,600\right.$ to $\left.1,700 \mathrm{~cm}^{-1}\right)$, and the third 
noise region was in the band affected by $\mathrm{O}-\mathrm{H}$ stretching $\left(>\sim 3,000 \mathrm{~cm}^{-1}\right)$. Although wavenumbers in the $\mathrm{O}-\mathrm{H}$ bending and $\mathrm{O}-\mathrm{H}$ stretching bands of the spectrum are often attributed as noise and removed, there is evidence that these regions contain valuable information. Wang et al. (2016) and Wang and Bovenhuis (2018) found wavenumbers in the regions between 1,619 and 1,674 $\mathrm{cm}^{-1}$ and 3,073 and $3,667 \mathrm{~cm}^{-1}$ that were affected by a polymorphism in the DGAT1 gene that has major effects on milk composition (Grisart et al., 2002). Similarly, Toledo-Alvarado et al. (2018a) reported a significant association between cows' pregnancy status and the $3,683 \mathrm{~cm}^{-1}$ wavenumber. Bittante and Cecchinato (2013) also showed that the transmittance for most FTIR wavenumbers in the range from 930 to 5,000 $\mathrm{cm}^{-1}$ was heritable. They concluded that, although heritabilities were often low in the water absorption regions from 1,586 to $1,698 \mathrm{~cm}^{-1}$ and 3,052 to 3,669 $\mathrm{cm}^{-1}$, these regions should still be considered for investigation, because they included absorbance peaks for chemical bonds related to non-water milk components.

The effect of including wavenumbers from noise regions in a study will depend on the specific application. In applications where wavenumbers are considered independently, such as in a single-wavenumber genome-wide association study, it is prudent to retain spectra from all wavenumbers in the analysis. However, in applications where wavenumbers are considered in a multivariate manner, such as in the evaluation of principal components or partial least squares regression,

(a) 649 to $<3999 \mathrm{~cm}^{-1}$

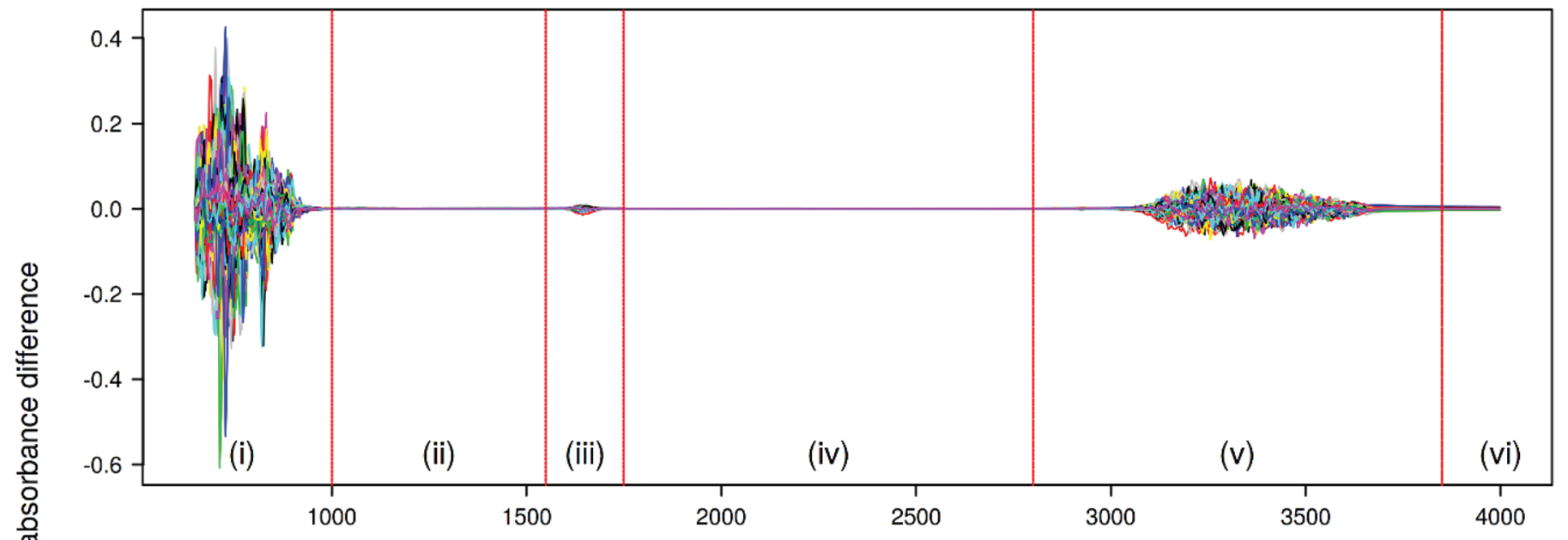

(b) $<1000 \mathrm{~cm}^{-1}$

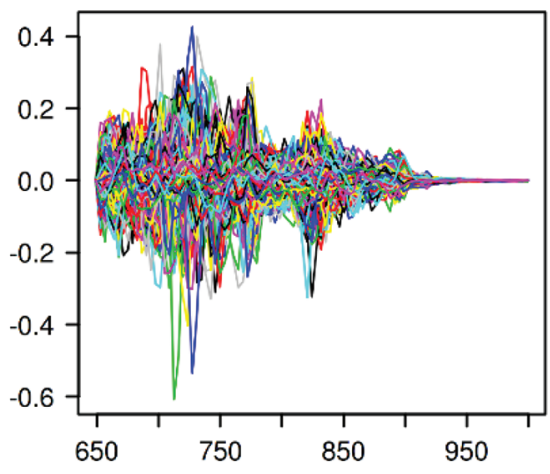

(c) 1550 to $1750 \mathrm{~cm}^{-1}$

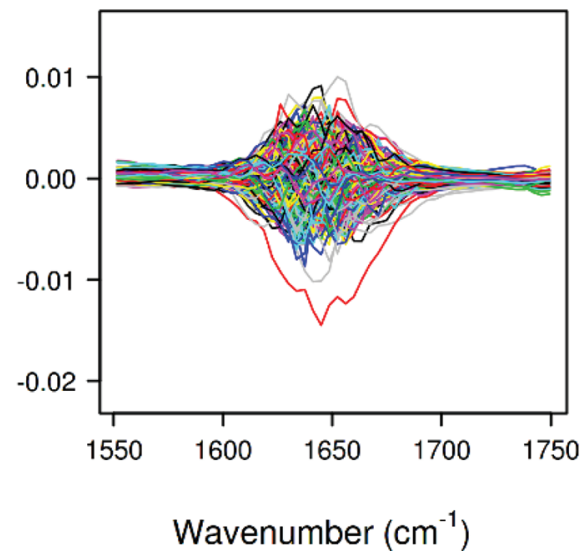

(d) 2800 to $3850 \mathrm{~cm}^{-1}$

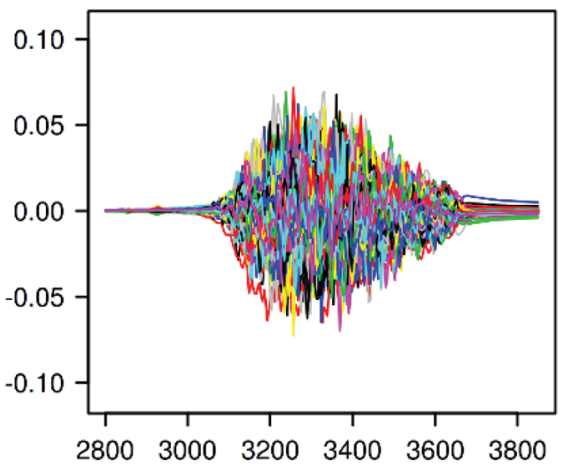

Figure 3. Absorbance differences for paired mid-infrared milk spectra wavenumbers, where absorbance $=\log (1 / T)$ and $T=\operatorname{transmittance.~}$ Results are based on paired-spectra $(\mathrm{n}=918)$ from reference samples analyzed across 6 Bentley FTS instruments (Bentley Instruments, Chaska, MN). Mid-infrared wavenumber regions defined as (i) 649 to $1,000 \mathrm{~cm}^{-1}$; (ii) 1,003 to $1,548 \mathrm{~cm}^{-1}$; (iii) 1,552 to $1,749 \mathrm{~cm}$; (iv) 1,753 to 2,798 $\mathrm{cm}^{-1}$; (v) 2,801 to $3,849 \mathrm{~cm}^{-1}$; and (vi) 3,853 to $3,999 \mathrm{~cm}^{-1}$. 
(i) $749.7 \mathrm{~cm}^{-1}$

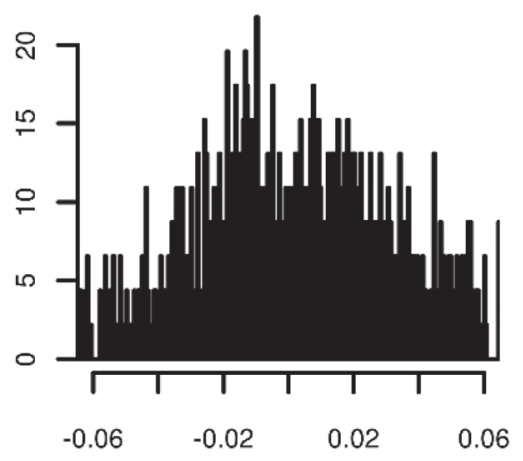

(iv) $2275.3 \mathrm{~cm}^{-1}$

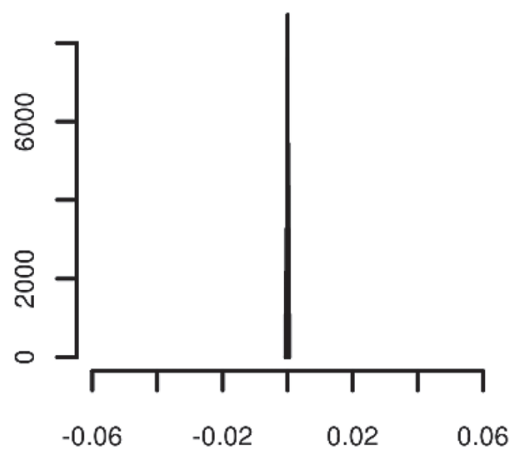

(ii) $1275.7 \mathrm{~cm}^{-1}$

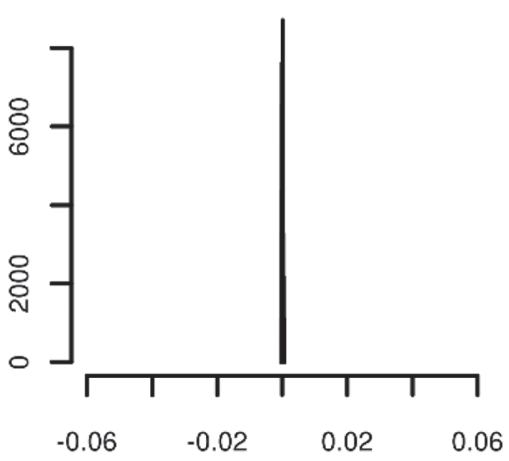

(v) $3323.5 \mathrm{~cm}^{-1}$

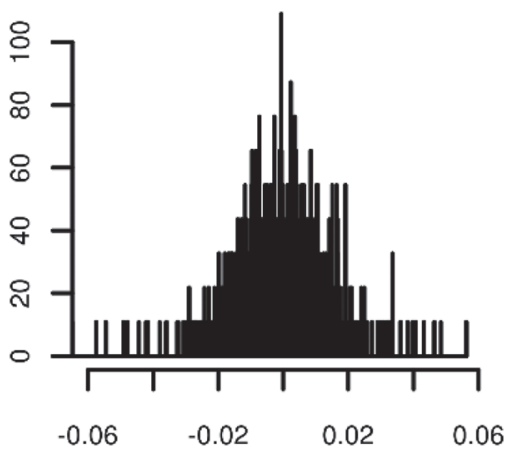

(iii) $1648.7 \mathrm{~cm}^{-1}$

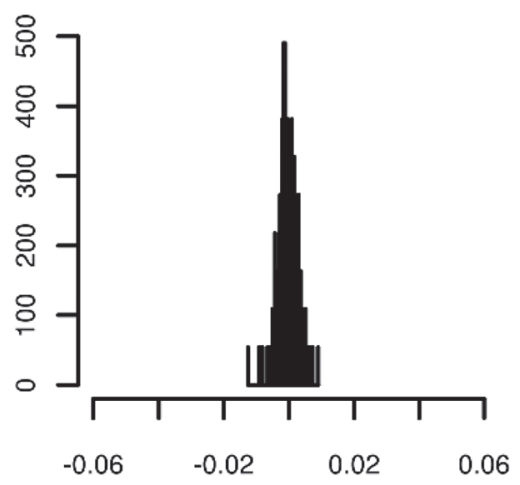

\section{Paired-spectra absorbance difference}

Figure 4. Representative distributions of absorbance differences for paired mid-infrared milk spectra at specified wavenumbers where absorbance $=\log (1 / T)$ and $T=$ transmittance. Results are based on paired-spectra $(\mathrm{n}=918)$ from reference samples analyzed across 6 Bentley FTS instruments (Bentley Instruments, Chaska, MN). Mid-infrared wavenumber regions defined as (i) 649 to $1,000 \mathrm{~cm}^{-1}$; (ii) 1,003 to $1,548 \mathrm{~cm}^{-1}$; (iii) 1,552 to $1,749 \mathrm{~cm}^{-1}$; (iv) 1,753 to $2,798 \mathrm{~cm}^{-1}$; (v) 2,801 to $3,849 \mathrm{~cm}^{-1}$; and (vi) 3,853 to $3,999 \mathrm{~cm}^{-1}$.

the exclusion of noise regions is an important step. For all subsequent applications in the present study, noise regions have been defined according to the Wasserstein distance metric with $\alpha=0.15$ (649 to $970 \mathrm{~cm}^{-1}, 1,608$ to $1,682 \mathrm{~cm}^{-1}$, and 3,021 to $\left.3,849 \mathrm{~cm}^{-1}\right)$. This definition provided boundaries similar to those previously report-

Table 1. Noise regions for mid-infrared milk spectra as defined by different paired-spectra difference metrics and varying $\alpha$ levels $^{1}$

\begin{tabular}{llccc}
\hline & & \multicolumn{2}{c}{ Noise region wavenumber ranges $\left(\mathrm{cm}^{-1}\right)$} \\
\cline { 3 - 5 } $\begin{array}{l}\text { Scaled paired-spectra } \\
\text { difference metric }\end{array}$ & $\begin{array}{l}\text { Noise region } \\
\text { number }\end{array}$ & $\alpha=0.05$ & $\alpha=0.1$ & $\alpha=0.15$ \\
\cline { 3 - 5 } Mean & 1 & $653-940$ & $649-959$ & $649-970$ \\
& 2 & $1,626-1,664$ & $1,615-1,675$ & $1,608-1,686$ \\
Standard deviation & 3 & $3,074-3,667$ & $3,040-3,737$ & $3,018-3,879$ \\
& 1 & $653-944$ & $649-962$ & $649-974$ \\
Wasserstein distance & 2 & $1,623-1,667$ & $1,611-1,679$ & $1,608-1,686$ \\
& 3 & $3,070-3,674$ & $3,036-3,801$ & $3,006-3,999$ \\
& 1 & $653-940$ & $649-955$ & $649-970$ \\
& 3 & $1,626-1,664$ & $1,615-1,675$ & $1,608-1,682$ \\
& 3 & $3,077-3,663$ & $3,044-3,726$ & $3,021-3,849$
\end{tabular}

${ }^{1}$ The $\alpha$ levels indicate the probability of falsely assigning a wavenumber to a noise region. 
ed (Soyeurt et al., 2010; Bittante and Cecchinato, 2013; Grelet et al., 2015). The resulting spectra with noise regions removed included only 526 of the 899 original wavenumbers.

\section{Outlier Removal for Milk Test Samples}

From 2,109,750 milk test records, 2,081,455 remained after outlier removal based on the MD for milk component concentrations. The distribution of MD values between each spectra record and the average spectra is presented in Figure 5. Also shown is the curve of the expected $\chi^{2}$ distribution with $526 \mathrm{df}$ and the corresponding critical-value threshold based on a $P$-value of 0.001 . The distribution of MD values for the spectra was not consistent with the expected $\chi^{2}$ distribution because of instrument-specific clustering. Therefore, outlier removal was conducted on within-instrument $\mathrm{MD}$ values.

Within-instrument MD values were calculated and the logistic distribution of best fit was determined. Within-instrument MD values are presented in Figure 6. Curves of the best-fit logistic distributions are also shown with outlier thresholds corresponding to a $P$ value of 0.001 . Within-instrument outlier thresholds ranged from 572 to 772 . Using these thresholds, $1.79 \%$ of records were identified as outliers and removed, leaving 2,044,094 records for analysis.

In studies of FTIR spectra, outlier removal using MD values is a common approach. However, many studies use spectra from only a single instrument and do not have the complexity of differing variance structures between instruments. Results in this study demonstrate the importance of accounting for instrument-specific variance structures when applying multivariate outlier identification methods. Failing to do so and applying a threshold based on a $\chi^{2}$ distribution with $526 \mathrm{df}$ would have resulted in removing a large proportion of records from one instrument and not removing anomalies from others.

\section{Assessment of PDS on Milk-Based Reference Samples}

Root mean square errors between primary- and secondary-instrument predictions from unstandardized and standardized reference sample spectra are presented in Table 2. Each of the PDS strategies resulted in lower RMSE values across milk component concentrations than the RMSE values from unstandardized spectra. The PDS:Weekly strategy resulted in the lowest RMSE values, with a reduction in RMSE from 0.222 to 0.022 $\mathrm{g} / 100 \mathrm{~mL}$ for fat, 0.265 to $0.020 \mathrm{~g} / 100 \mathrm{~mL}$ for protein, and 0.299 to $0.010 \mathrm{~g} / 100 \mathrm{~mL}$ for lactose. A recent study

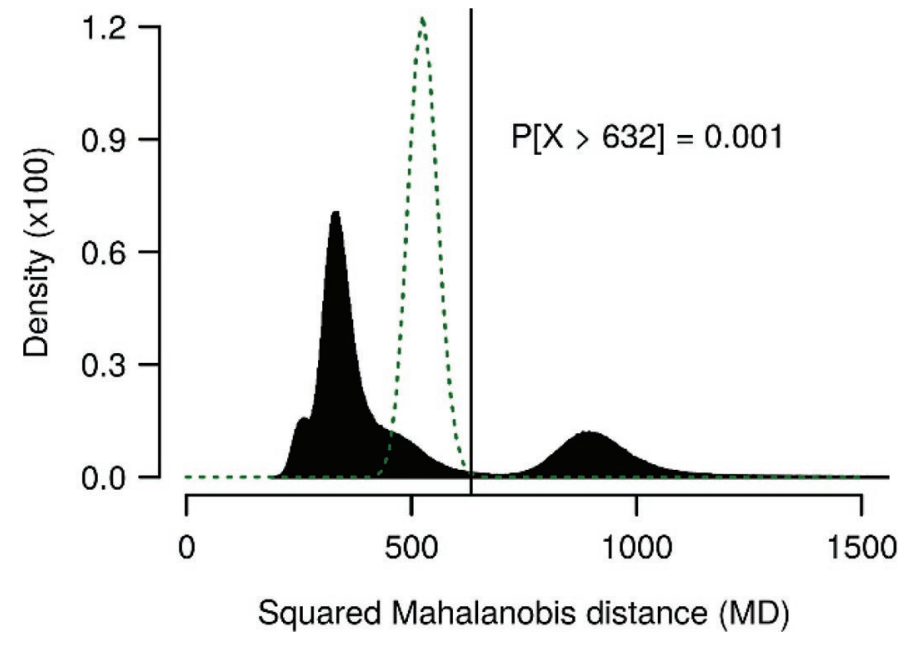

Figure 5. Squared Mahalanobis distance distribution (MD) across herd test records $(\mathrm{n}=2,081,445)$. The curve of the expected $\chi^{2}$ distribution with 526 degrees of freedom is also shown with the corresponding critical-value threshold associated with a $P$-value of 0.001 .

reported a comparable RMSE between primary- and secondary-instrument predictions after standardization of $0.016 \mathrm{~g} / 100 \mathrm{~mL}$ for fat (Grelet et al., 2015). That study used a similar approach to our PDS:Weekly strategy, in that the spectra for each week were also included in the records used to evaluate standardization coefficients. This approach is likely to underestimate prediction errors when coefficients are applied to different spectral data sets. The PDS:AllOtherWks and PDS:Monthly strategies were structured to ensure that for any given week, the spectra for the week being assessed were independent of the spectra used to evaluate the coefficients being applied to that week. Of these 2 strategies, the PDS:AllOtherWks strategy resulted in the lowest RMSE values; that is, $0.059 \mathrm{~g} / 100 \mathrm{~mL}$ for fat, $0.051 \mathrm{~g} / 100 \mathrm{~mL}$ for protein, and $0.053 \mathrm{~g} / 100 \mathrm{~mL}$ for lactose (Table 2). These RMSE values equate to a reduction of $73 \%$ for fat, $81 \%$ for protein, and $82 \%$ for lactose. These reductions in RMSE were similar to those presented by Grelet et al. (2017) for methane emissions (83\%), polyunsaturated fatty acids (86\%), and cheese yield (81\%).

Relationships between primary- and secondaryinstrument predictions from unstandardized and standardized spectra based on PDS:AllOtherWks and PDS: Monthly coefficient sets are presented in Figure 7. After standardization, bias and deviation from unity for slopes consistently decreased and $\mathrm{R}^{2}$ values consistently increased. Slope deviations from 1 after standardization were $<0.02$ for fat and protein concentrations. For lactose, the deviation from 1 before standardization was high at 0.75 , but was reduced to $<0.17$ after standardization. The highest bias levels between primary- and 
A1

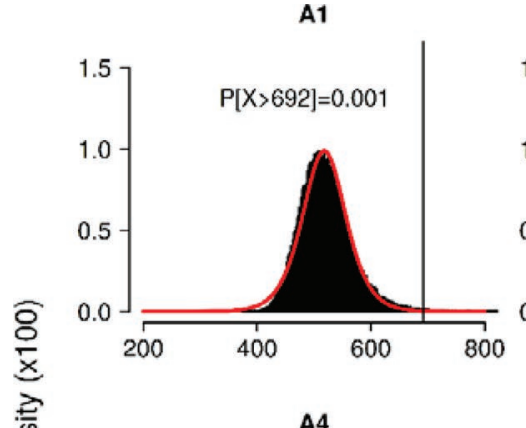

A2

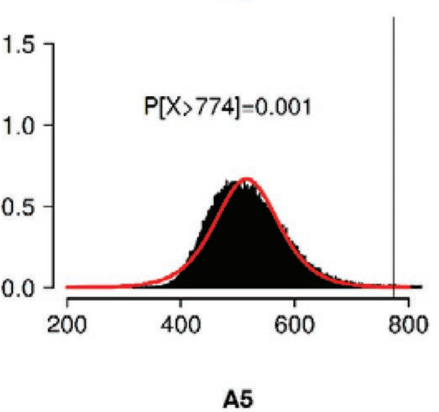

A3

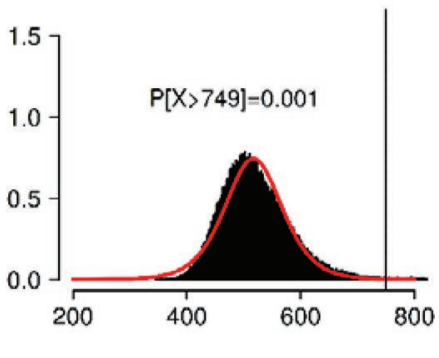

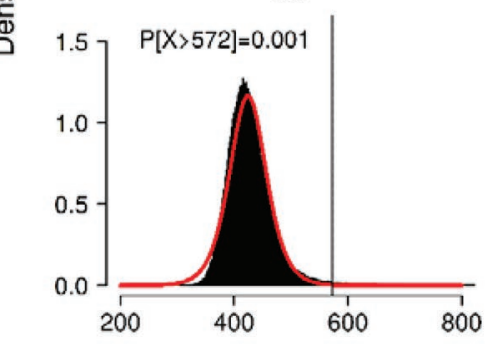

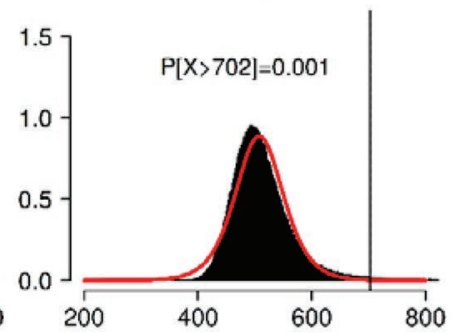

A6

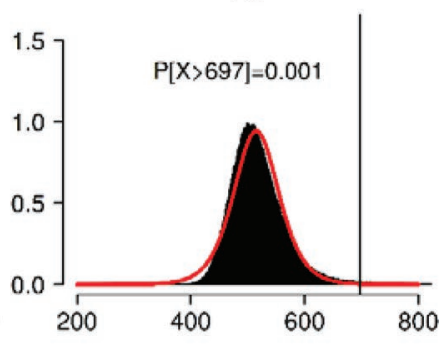

Squared Mahalanobis distance (MD)

Figure 6. Within-instrument (where A1 to A6 are instruments) squared Mahalanobis distance (MD) distributions and corresponding critical-value thresholds associated with a $P$-value of 0.001 , based on approximated logistic distributions with location and scale parameters, respectively: A1: 518.4, 29.2; A2: 516.3, 42.1; A3: 517.8, 37.0; A4: 420.8, 20.6; A5: 509.1, 37.8; and A6: 515.8, 31.2 (A1: $\mathrm{n}=191,655 ; \mathrm{A} 2: \mathrm{n}=$ $200,612 ; \mathrm{A} 3: \mathrm{n}=157,691 ; \mathrm{A} 4: \mathrm{n}=430,940 ; \mathrm{A} 5: \mathrm{n}=461,130 ; \mathrm{A} 6: \mathrm{n}=639,427)$.

secondary-instrument predictions were observed for lactose concentrations. Before standardization, the bias was $3.56 \mathrm{~g} / 100 \mathrm{~mL}$, but this was reduced to $0.41 \mathrm{~g} / 100$ $\mathrm{mL}$ using the PDS:AllOtherWks strategy.

Figure 8 presents relative RMSE values between primary- and secondary-instrument predictions from standardized spectra using PDS:RollingWks strategies, where $w=1$ to 8 represents the number of previous

Table 2. Root mean squared errors (RMSE) between primary- and secondary-instrument trait predictions from unstandardized and standardized spectra $(\mathrm{n}=79)^{1}$

\begin{tabular}{lccc}
\hline & \multicolumn{3}{c}{ Trait $(\mathrm{g} / 100 \mathrm{~mL})$} \\
\cline { 2 - 4 } Strategy & Fat & Protein & Lactose \\
\hline Standardized $^{2}$ & & & \\
PDS:Weekly & 0.022 & 0.020 & 0.010 \\
PDS:AllOtherWks & 0.059 & 0.051 & 0.053 \\
PDS:Monthly & 0.080 & 0.066 & 0.054 \\
Unstandardized & 0.222 & 0.265 & 0.299 \\
\hline
\end{tabular}

${ }^{1}$ Standardization conducted using implementations of the piecewise direct standardization (PDS) method. Results are shown for weeks $k$ $=9$ to 16 (8-wk validation period from April to May 2018).

${ }^{2}$ For each week $k$, PDS coefficients were evaluated and applied. PDS: Weekly $=$ standardized using PDS coefficient sets from reference samples from week $k$ only; PDS:AllOtherWks = standardized using PDS coefficients evaluated from reference samples from all other weeks, except week $k$; and PDS:Monthly = standardized using PDS coefficients evaluated from reference samples from all weeks in the same calendar month as week $k$, but excluding week $k$. weeks of spectra included in standardization coefficient set evaluation. For fat and protein, relative RMSE values between primary- and secondary-instrument predictions decreased as additional weeks of historical data were used to evaluate coefficients, but incremental benefits diminished as more weeks were added. For lactose, the relative RMSE values were consistently low at $\sim 1 \%$ regardless of the number of previous weeks of data used to evaluate coefficient sets.

Including spectra from a wider date range in coefficient set evaluations resulted in lower prediction errors. This was evident from the lower RMSE values for the PDS:AllOtherWks strategy (Table 2) and was confirmed by the trends in relative RMSE for the PDS: RollingWks strategies (Figure 8). However, the present study included reference sample spectra from a 16 -wk period only. Over a longer period, we could expect further instrument drift and shifts in the spectra due to instrument maintenance, deterioration or replacement of parts, and factors such as temperature fluctuations and wavelength or detector intensity instability (Wang et al., 1991). Major shifts in the spectra due to these factors would affect relationships between primary- and secondary-instrument spectra and potentially erode gains in prediction accuracy. Monitoring and adjusting for drift and spectra shifts is thus important to ensure that standardization using the PDS approach consistently reduces prediction errors across time. 
Unstandardized
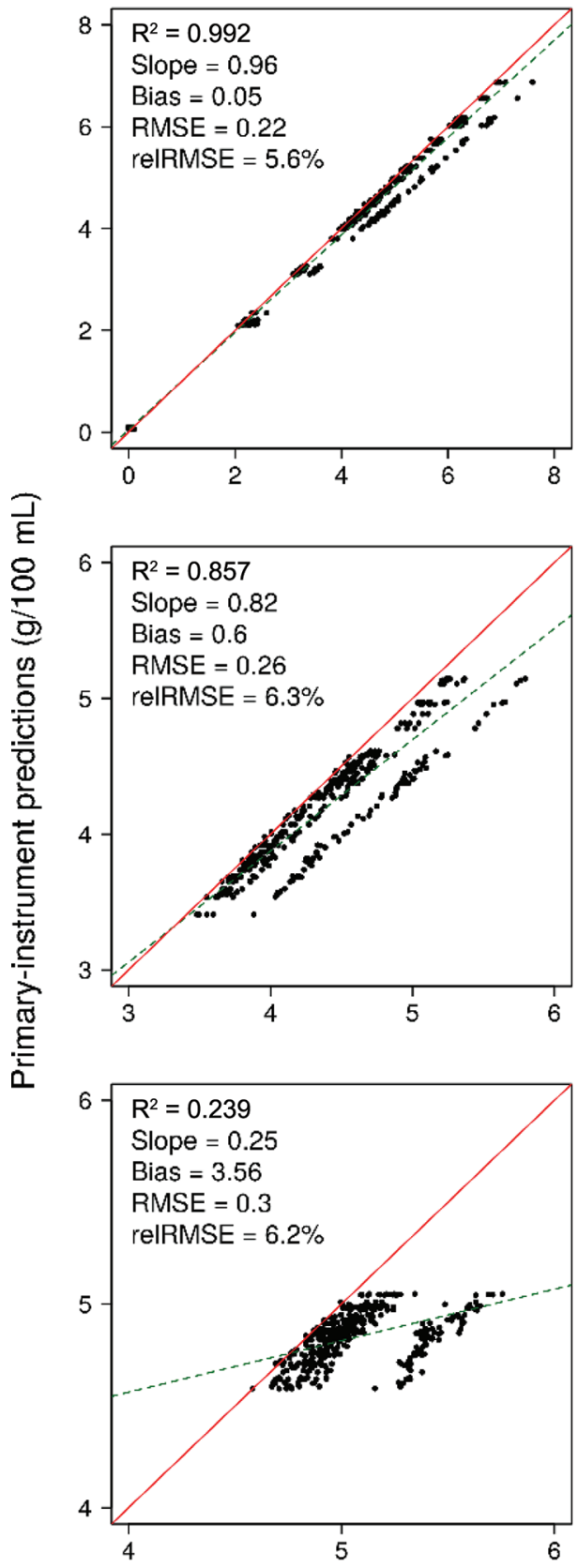

Standardized - PDS:AllOtherWks
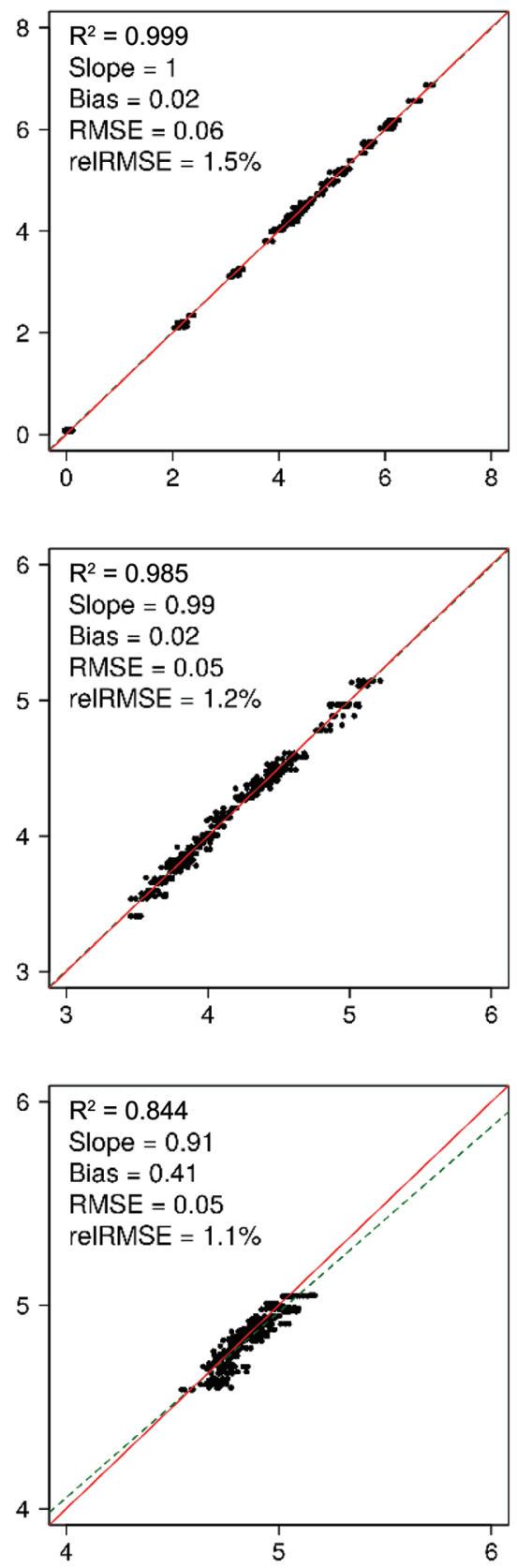

Standardized - PDS:Monthly

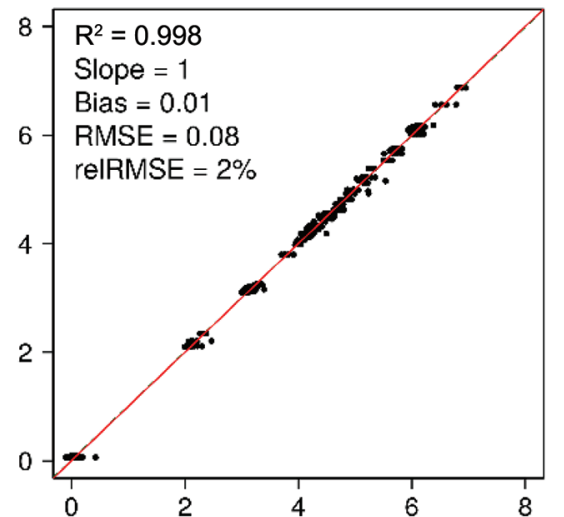

满
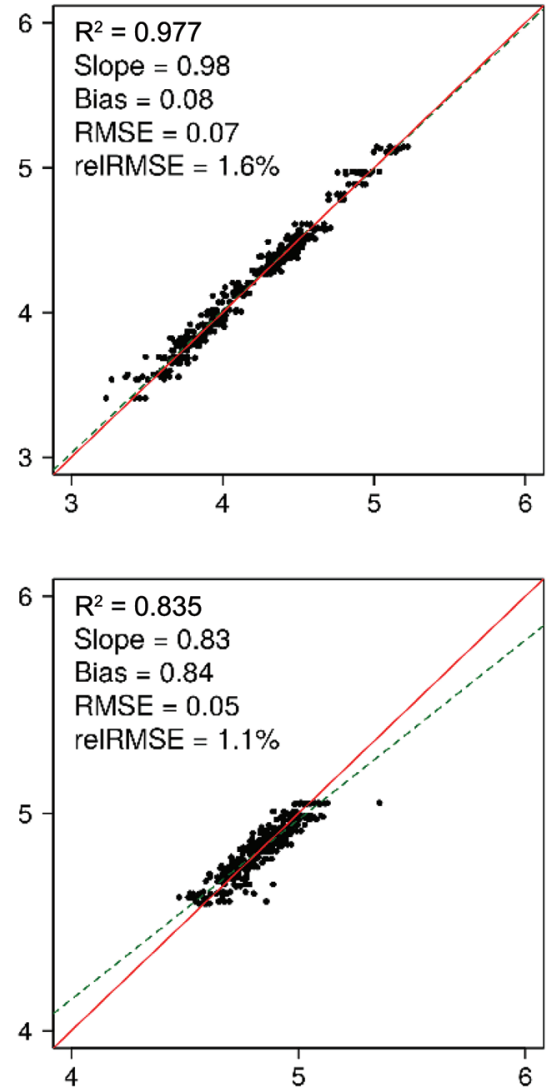

Secondary-instrument predictions $(\mathrm{g} / 100 \mathrm{~mL})$

Figure 7. Comparison between primary- and secondary-instrument predictions based on unstandardized and standardized spectra from implementations of the piecewise direct standardization (PDS) method. Results are shown for weeks $k=9$ to 16 (8-wk validation period from April to May 2018; $\mathrm{n}=79$ ). For each week $k$, PDS coefficients were evaluated and applied. PDS:AllOtherWks = standardized using PDS coefficients evaluated from reference samples from all other weeks, except week $k$; and PDS:Monthly $=$ standardized using PDS coefficients evaluated from reference samples from all weeks in the same calendar month as week $k$, but excluding week $k$. Dotted lines represent the regression line between primary and secondary instruments; continuous line represents $\mathrm{y}=\mathrm{x}$. RMSE $=$ root mean squared error; relRMSE $=$ relative RMSE. 


\section{Assessment of PDS and RPS on Milk Test Samples}

Root mean square errors between industry-standard predictions of milk components and predictions from unstandardized and standardized spectra are presented in Table 3. Standardization resulted in lower RMSE values for all strategies and across all examined milk components. The 2 most effective strategies for reducing prediction errors were PDS:Overall and RPS: Month$1 y^{\text {Is }}$. The RPS strategies that standardized secondary instruments to a common North Island primary instrument (RPS:Overall, RPS:Monthly) did not perform as well at reducing prediction errors compared with the RPS:Monthly ${ }^{\text {Is }}$ strategy that standardized spectra from South Island samples to a South Island instrument.

The PDS:Overall strategy resulted in the lowest RMSE for fat with a decrease from 0.190 to $0.071 \mathrm{~g} / 100$ $\mathrm{mL}$; that is, a reduction of $63 \%$. The RPS:Monthly ${ }^{\text {Is }}$ strategy resulted in the lowest RMSE for protein with a decrease from 0.129 to $0.049 \mathrm{~g} / 100 \mathrm{~mL}$ for protein; that is, a reduction of $62 \%$. For lactose, standardization using the PDS:Overall strategy resulted in a decrease in RMSE from $0.143 \mathrm{~g} / 100 \mathrm{~mL}$ to $0.088 \mathrm{~g} / 100$ $\mathrm{mL}$ (a reduction of $38 \%$ ). This reduction in RMSE was lower than that for the RPS:Monthly ${ }^{\mathrm{Is}}$ strategy, which had a decrease in RMSE to $0.061 \mathrm{~g} / 100 \mathrm{~mL}$ (a $57 \%$ reduction). A likely reason for the PDS strategy not performing as well for lactose is that only a small range of lactose values $(\sim 4.7$ to $5 \mathrm{~g} / 100 \mathrm{~mL})$ were represented in the reference samples used to evaluate PDS coefficients. Wider component concentration ranges in reference samples improve trait calibrations (Kaylegian et al., 2006). This implies that representation
Table 3. Root mean squared errors (RMSE) between industrystandard trait predictions and predictions from unstandardized and standardized spectra $(\mathrm{n}=2,044,094)$

\begin{tabular}{lccc}
\hline & \multicolumn{3}{c}{ Trait $(\mathrm{g} / 100 \mathrm{~mL})$} \\
\cline { 2 - 4 } Strategy & Fat & Protein & Lactose \\
\hline Standardization $^{1}$ & & & \\
PDS:Overall $_{\text {RPS:Overall }}$ & 0.071 & 0.055 & 0.088 \\
RPS:Monthly & 0.156 & 0.085 & 0.087 \\
RPS:Monthly & 0.142 & 0.081 & 0.080 \\
Unstandardised $^{\text {Is }}$ & 0.076 & 0.049 & 0.061 \\
& 0.190 & 0.129 & 0.143
\end{tabular}

${ }^{1} \mathrm{PDS}$ :Overall $=$ standardized using piecewise direct standardization (PDS) coefficients evaluated from all reference samples; RPS:Overall = standardized using retroactive percentile standardization (RPS) coefficients evaluated from all herd test samples; RPS:Monthly $=$ standardized using RPS coefficient sets evaluated monthly from herd test samples; and RPS Monthly ${ }^{\text {Is }}=$ standardized using RPS coefficient sets evaluated monthly from herd test samples with a different primary instrument used for South Island samples.

of a wider range of lactose values in reference samples would improve the mapping of relationships between primary- and secondary-instrument wavenumbers that have absorbance peaks for lactose. This would improve lactose predictions when using the PDS approach and improve predictions for other traits that have spectral signal represented across the same wavenumbers.

Variation in Individual Instrument Prediction Accuracy. Figure 9 presents relative RMSE values between industry-standard milk component predictions and predictions from unstandardized and standardized spectra, summarized by instrument. Two of the South Island instruments (A2, A3) had consistently high relative RMSE values for unstandardized spectra com-
Fat

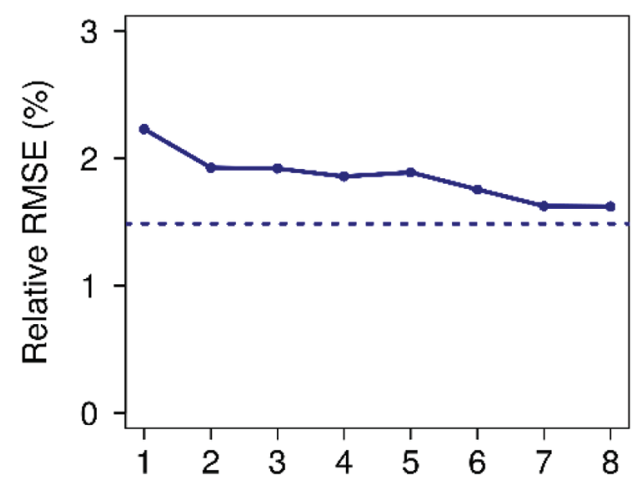

Protein

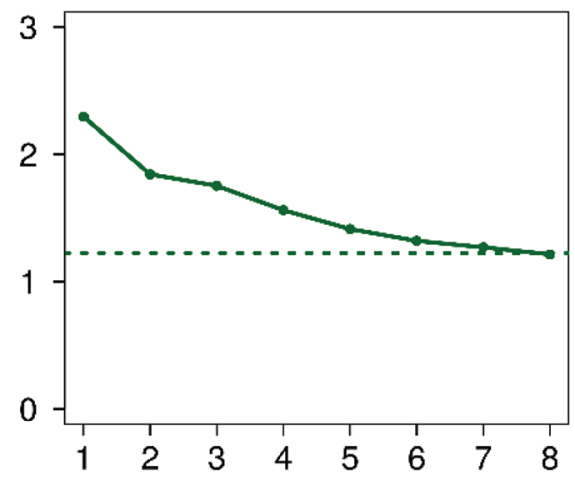

Lactose

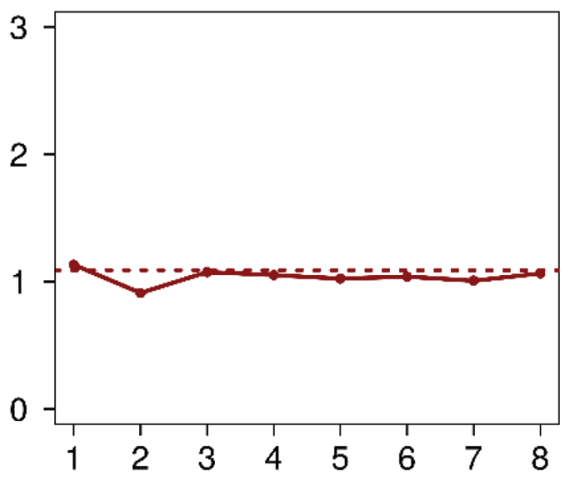

Number of previous weeks $(w)$ of spectra included in standardization coefficients applied to each week

Figure 8. Relative root mean squared errors (RMSE) between primary- and secondary-instrument predictions for spectra standardized using piecewise direct standardization (PDS). Results are shown for weeks $k=9$ to 16 (8-wk validation period from April to May 2018; $\mathrm{n}=79$ ). The $\mathrm{X}$-axis represents the number of previous weeks of reference sample spectra included in the evaluation of standardization coefficients applied to each week. Dotted lines represent the relative RMSE from the PDS:AllOtherWks strategy (i.e., each week standardized using PDS coefficients evaluated from reference sample spectra from all other weeks). 

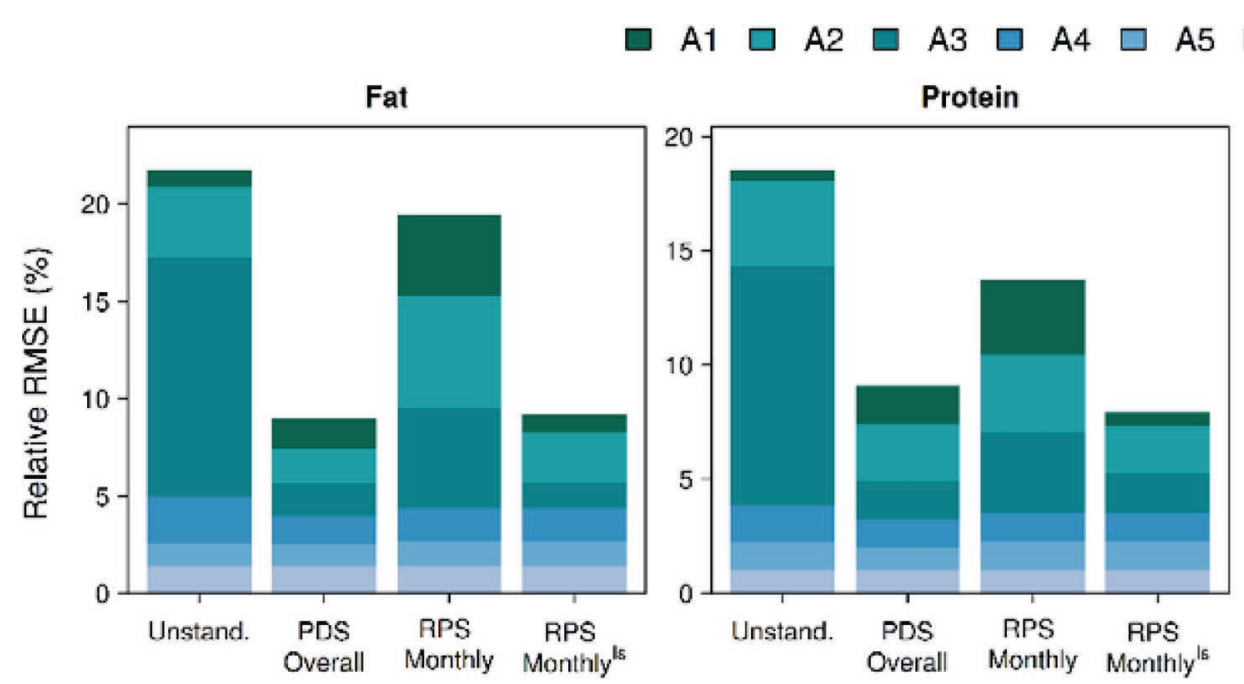

A6

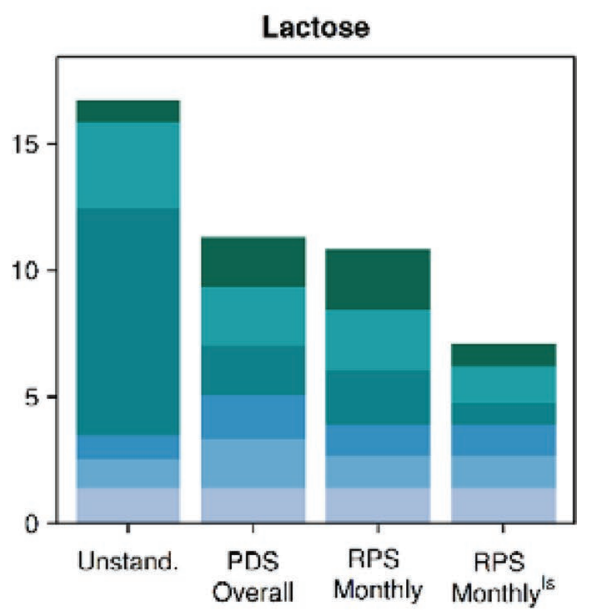

Standardization strategy

Figure 9. Relative root mean squared errors (RMSE) between industry-standard milk component predictions and predictions from unstandardized and standardized spectra, summarized by instrument $(\mathrm{n}=2,044,094)$. Standardization conducted using implementations of the piecewise direct standardization (PDS) and retroactive percentile standardization (RPS) methods. Unstand = unstandardized; PDS Overall = standardized using PDS coefficients evaluated from all reference samples; RPS Monthly = standardized using RPS coefficient sets evaluated

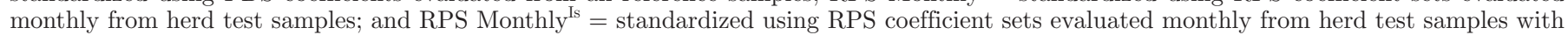
a different primary instrument used for South Island samples.

pared with the other instruments. The PDS:Overall strategy had consistently low RMSE values, even for the A2 and A3 instruments. For all milk components, after standardizing using the RPS:Monthly strategy, relative RMSE values were inflated for South Island instruments. When spectra from South Island samples were standardized to a South Island instrument (RPS: Monthly ${ }^{\text {Is }}$, RMSE values were reduced to similar levels as the PDS:Overall strategy for fat and were lower for protein and lactose.

Variation in Prediction Accuracy over Time. Figure 10 presents relative RMSE values between industry-standard milk component predictions and predictions from unstandardized and standardized spectra, summarized by month. The PDS:Overall strategy had consistently low relative RMSE values across all months for all milk components. Notably, the PDS: Overall strategy standardizes the full season of herd test spectra using only one set of standardization coefficients, evaluated from reference samples for the 16-wk period from February to May 2018.

Consistently low relative RMSE values were also observed for the RPS:Monthly ${ }^{\text {Is }}$ strategy, except for peaks for fat and protein in May. On closer examination, these peaks were caused by high relative RMSE values for 2 of the instruments (A2, A4). The likely cause of this was the decrease in overall spectra record numbers included in the estimation of standardization coefficients for May. Between April and May, the number of spectra records decreased by $65 \%$ for the North Island and by $68 \%$ for the South Island.

Implementing the RPS strategy with monthly coefficient updates and standardizing to a common North Island primary instrument (RPS:Monthly) was not as effective at reducing prediction errors as the RPS: Monthly ${ }^{\text {Is }}$ approach. Using the RPS:Monthly strategy resulted in prediction error peaks for fat in January and May and for protein in April and May. On closer examination, high relative RMSE values for South Island instruments (A1, A2, A3) were underlying these peaks. These were caused by differences in milk component concentrations for North and South Island samples in these months: average industry-standard predictions for fat in January were $5.10 \mathrm{~g} / 100 \mathrm{~mL}$ for North Island samples compared with $4.68 \mathrm{~g} / 100 \mathrm{~mL}$ for South Island samples (i.e., 9\% higher); in May, average industrystandard predictions for fat were $5.48 \mathrm{~g} / 100 \mathrm{~mL}$ for North Island samples compared with $5.91 \mathrm{~g} / 100 \mathrm{~mL}$ for South Island samples (i.e., 7\% lower). Differences between fat concentrations for North and South Island samples were also observed in other months but were smaller. Similar trends were observed for protein in April and May.

In general, regional and island differences in milk composition across the season are expected because of genetic factors such as regional breed structure and other region-specific factors related to feed, management, calving start dates, and climate or weather pat- 
terns. For this reason, it is unsurprising that differences in milk composition were observed between North and South Island samples, particularly in January and in April/May. January is the peak of summer in New Zealand, a time when farmers adopt varying practices to manage feed and maintain body condition score targets. From March onward, differences in milk composition are to be expected as cows are dried off, with drying off taking place 2 to $3 \mathrm{wk}$ later, on average, in the South Island than in the North Island.

The expectation is that milk composition on average across instruments within a center would be equivalent because milk test samples are randomly allocated to instruments within each milk-testing center. However, overall differences in milk composition for samples processed in the North Island compared with those processed in the South Island would not necessarily be expected to be equivalent. These milk composition differences became problematic when using the RPS: Monthly approach, which standardizes spectra from South Island samples to a North Island primary instrument. In doing so, other non-instrument errors and bias were introduced. The risk of correcting for noninstrument factors such as breed and feed when using a retroactive approach was also signaled by Grelet et al. (2017). In the present study, we were able to resolve this by partitioning spectra into subsets and applying standardization within month and with a separate primary instrument assigned for each of the North and South Islands. Partitioning spectra into homogeneous subsets for the purpose of standardization can also be achieved using principal components analysis (PCA) to detect shifts in the PCA scores across time as per Bonfatti et al. (2017a). In their study, Bonfatti et al. (2017a) also demonstrated the importance of standardization within homogeneous sets of spectra and confirmed that small variations in the FTIR signal could lead to prediction inaccuracies. They concluded that the RPS method should be considered complementary to other classical standardization procedures, and that variability in signal across time should be monitored carefully.

\section{Common Reference Sample Sharing Between Networks}

Standardization using the PDS method consistently reduced prediction errors across time compared with no standardization or standardizing using the RPS method. This was evident in the application of the PDS: AllOtherWks approach applied to reference samples and in the PDS:Overall approach applied to milk test samples. Applications of the PDS method rely on the analysis of identical reference samples across all instruments in the network. To be able to standardize predictions across multiple networks, including those in other countries, requires the sharing of common reference samples. In Europe, reference sample sharing and standardization between instruments in different countries already takes place across the OptiMIR network. This transnational network includes $\sim 65$ FTIR spectrometers in 25 milk laboratories across 5 countries, with standardization data being stored in a common data-

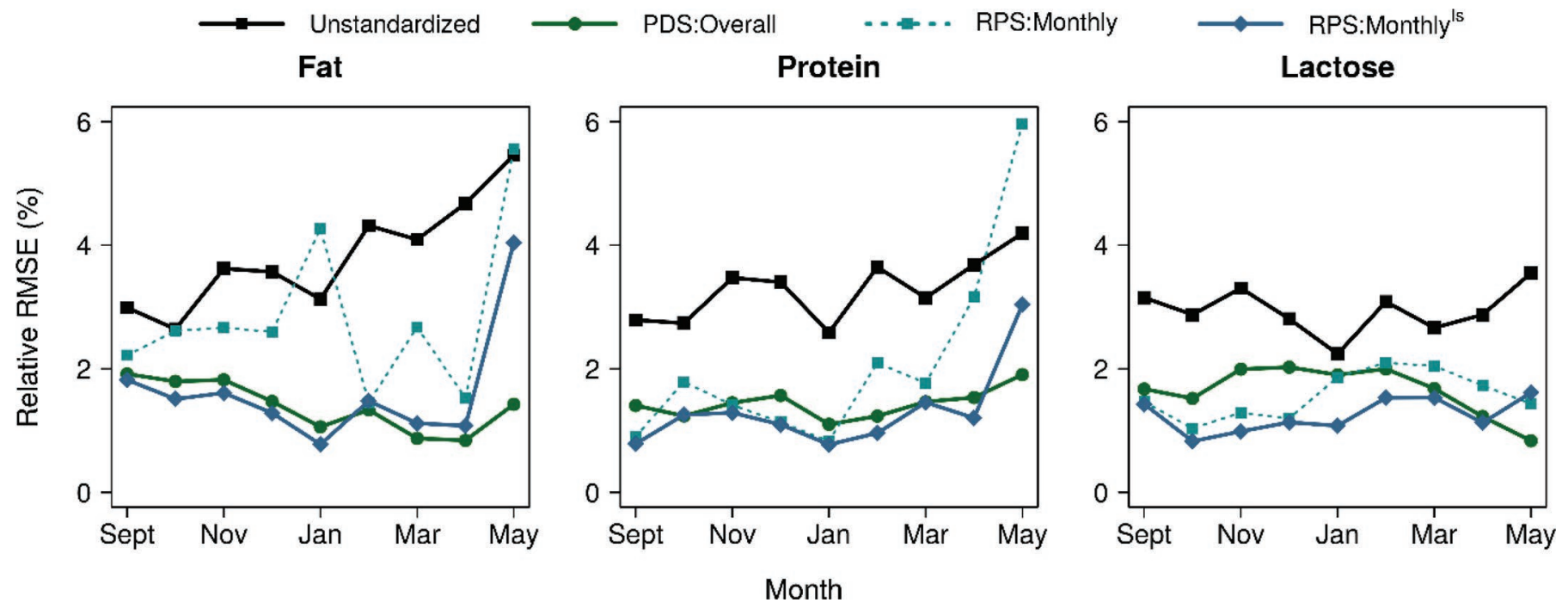

Figure 10. Relative root mean squared errors (RMSE) between industry-standard milk component predictions and predictions from unstandardized and standardized spectra, summarized by month $(\mathrm{n}=2,044,094)$. PDS:Overall = standardized using piecewise direct standardization (PDS) coefficients evaluated from all reference samples; RPS:Monthly = standardized using retroactive percentile standardization (RPS) coef-

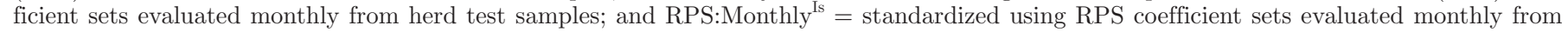
herd test samples with a different primary instrument used for South Island samples. 
base (European Economic Interest Grouping, undated). Outside Europe, there is little in the way of sharing or analyzing common reference samples between countries. Sharing reference samples globally has the potential to enhance collaboration opportunities and maximize the value of FTIR spectra. However, the success of this would require the resolution of several key issues, such as logistics, sample preservation and integrity, and other biosecurity-related risks. Also, it would be ideal if shared reference sample sets were extended to include a broader range of milk component representation as well as a wider range of individual component values. Several milk components have been confirmed as having absorbance peaks for chemical bonds within specific ranges of the mid-infrared spectrum (De Marchi et al., 2009; Grelet et al., 2015). If reference samples were extended to capture greater signal diversity across the spectrum, accuracies across a wider range of individual wavenumbers would be improved, which would result in improved predictions for other new traits.

\section{CONCLUSIONS}

In this study, we present strategies to reduce the impact of noise in FTIR spectra and compare standardization methods for reducing between-instrument variation. We demonstrated that standardization using a PDS approach gave the most consistent reduction in prediction errors across time. Standardization using the RPS approach can also be highly effective at reducing prediction errors, provided that secondary instruments are standardized to a primary instrument with broadly equivalent milk composition. Standardization using PDS is the optimal approach because it is less sensitive to shifts in milk composition and non-instrument errors. However, this method relies on having spectra from identical reference samples analyzed across all instruments in the network. Where reference sample spectra are unavailable, standardization using the RPS approach can be a suitable alternative. For implementations of either of these standardization methods, instrument drift and other major shifts in the spectra across time should be monitored carefully. Standardization to reduce between-instrument variation will improve the quality of FTIR spectra for various downstream applications, including for trait prediction, prediction of breeding values, and quantification of genetic signals underlying specific FTIR spectra wavenumbers.

\section{ACKNOWLEDGMENTS}

The authors gratefully acknowledge the LIC (Hamilton, New Zealand) herd-testing staff for the processing and analysis of milk samples. Kathryn Tiplady thanks the wider LIC R\&D team and fellow students for helpful discussions and underlying technical support. The authors gratefully acknowledge Tod Schilling and Pierre Broutin (Bentley Instruments Inc., Chaska, MN) for assistance with accessing FTIR spectra from Bentley instruments. This project was funded by LIC (Hamilton, New Zealand) in association with Massey University (Palmerston North, New Zealand).

\section{REFERENCES}

Bittante, G., and A. Cecchinato. 2013. Genetic analysis of the Fouriertransform infrared spectra of bovine milk with emphasis on individual wavelengths related to specific chemical bonds. J. Dairy Sci. 96:5991-6006. https://doi.org/10.3168/jds.2013-6583.

Bittante, G., and C. Cipolat-Gotet. 2018. Direct and indirect predictions of enteric methane daily production, yield, and intensity per unit of milk and cheese, from fatty acids and milk Fouriertransform infrared spectra. J. Dairy Sci. 101:7219-7235. https:// doi.org/10.3168/jds.2017-14289.

Bonfatti, V., A. Fleming, A. Koeck, and F. Miglior. 2017a. Standardization of milk infrared spectra for the retroactive application of calibration models. J. Dairy Sci. 100:2032-2041. https://doi.org/ 10.3168/jds.2016-11837.

Bonfatti, V., D. Vicario, A. Lugo, and P. Carnier. 2017b. Genetic parameters of measures and population-wide infrared predictions of 92 traits describing the fine composition and technological properties of milk in Italian Simmental cattle. J. Dairy Sci. 100:55265540. https://doi.org/10.3168/jds.2016-11667.

Cecchinato, A., A. Albera, C. Cipolat-Gotet, A. Ferragina, and G. Bittante. 2015. Genetic parameters of cheese yield and curd nutrient recovery or whey loss traits predicted using Fourier-transform infrared spectroscopy of samples collected during milk recording on Holstein, Brown Swiss, and Simmental dairy cows. J. Dairy Sci. 98:4914-4927. https://doi.org/10.3168/jds.2014-8599.

De Marchi, M., C. C. Fagan, C. P. O'donnell, A. Cecchinato, R. Dal Zotto, M. Cassandro, M. Penasa, and G. Bittante. 2009. Prediction of coagulation properties, titratable acidity, and $\mathrm{pH}$ of bovine milk using mid-infrared spectroscopy. J. Dairy Sci. 92:423-432. https://doi.org/10.3168/jds.2008-1163.

De Marchi, M., V. Toffanin, M. Cassandro, and M. Penasa. 2014 Invited review: Mid-infrared spectroscopy as phenotyping tool for milk traits. J. Dairy Sci. 97:1171-1186. https://doi.org/10.3168/ jds.2013-6799.

Delignette-Muller, M. L., and C. Dutang. 2015. fitdistrplus: An R package for fitting distributions. J. Stat. Softw. 64:1-34. http:// www.jstatsoft.org/v64/i04/.

European Economic Interest Grouping. Undated. Standardisation of MIR spectrometers across OptiMIR network. Accessed Sep. 28, 2018. https://www.milkrecording.eu/emr.site/index.php/ dairystat/.

Grelet, C., C. Bastin, M. Gelé, J. B. Davière, M. Johan, A. Werner, R. Reding, J. F. Pierna, F. G. Colinet, P. Dardenne, and N. Gengler. 2016. Development of Fourier transform mid-infrared calibrations to predict acetone, $\beta$-hydroxybutyrate, and citrate contents in bovine milk through a European dairy network. J. Dairy Sci. 99:4816-4825. https://doi.org/10.3168/jds.2015-10477.

Grelet, C., J. F. Pierna, P. Dardenne, V. Baeten, and F. Dehareng. 2015. Standardization of milk mid-infrared spectra from a European dairy network. J. Dairy Sci. 98:2150-2160. https://doi.org/ $10.3168 /$ jds.2014-8764.

Grelet, C., J. F. Pierna, P. Dardenne, H. Soyeurt, A. Vanlierde, F. Colinet, C. Bastin, N. Gengler, V. Baeten, and F. Dehareng. 2017. Standardization of milk mid-infrared spectrometers for the transfer and use of multiple models. J. Dairy Sci. 100:7910-7921. https: //doi.org/10.3168/jds.2017-12720.

Grisart, B., W. Coppieters, F. Farnir, L. Karim, C. Ford, P. Berzi, N. Cambisano, M. Mni, S. Reid, P. Simon, R. Spelman, M. Georges, 
and R. Snell. 2002. Positional candidate cloning of a QTL in dairy cattle: identification of a missense mutation in the bovine DGAT1 gene with major effect on milk yield and composition. Genome Res. 12:222-231. https://doi.org/10.1101/gr.224202.

ICAR (International Committee for Animal Recording). 2017. ICAR Guidelines. Section 12 - Guidelines for Milk Analysis. www.icar .org/Guidelines/12-Milk-Analysis.pdf.

ISO (International Organization for Standardization). 2007. Milk and milk products-Determination of lactose content by high-performance liquid chromatography (Reference method). Standard number 22662:2007. ISO, Geneva, Switzerland.

ISO (International Organization for Standardization). 2010. Milk-Determination of fat content-Gravimetric method (Reference method). Standard number 1211:2010. ISO, Geneva, Switzerland.

ISO (International Organization for Standardization). 2013. Milk and liquid milk products - Guidelines for the application of mid-infrared spectrometry. Standard number 9622:2013. ISO, Geneva, Switzerland.

ISO (International Organization for Standardization). 2016. Milk and milk products-Determination of nitrogen content-Part 4: Determination of protein and non-protein nitrogen content and true protein content calculation (Reference method). Standard number 8968-4:2016. ISO, Geneva, Switzerland.

Kaylegian, K. E., G. E. Houghton, J. M. Lynch, J. R. Fleming, and D. M. Barbano. 2006. Calibration of infrared milk analyzers: Modified milk versus producer milk. J. Dairy Sci. 89:2817-2832. https://doi .org/10.3168/jds.S0022-0302(06)72555-3.

Lainé, A., C. Bastin, C. Grelet, H. Hammami, F. G. Colinet, L. M. Dale, A. Gillon, J. Vandenplas, F. Dehareng, and N. Gengler. 2017. Assessing the effect of pregnancy stage on milk composition of dairy cows using mid-infrared spectra. J. Dairy Sci. 100:28632876. https://doi.org/10.3168/jds.2016-11736.

LIC (Livestock Improvement Corporation) and DairyNZ. 2017. New Zealand Dairy Statistics 2016-17. LIC/Dairy NZ, Hamilton, New Zealand.

Lopez-Villalobos, N., R. J. Spelman, J. Melis, S. R. Davis, S. D. Berry, K. Lehnert, S. E. Holroyd, A. K. MacGibbon, and R. G. Snell. 2014. Estimation of genetic and crossbreeding parameters of fatty acid concentrations in milk fat predicted by mid-infrared spectroscopy in New Zealand dairy cattle. J. Dairy Res. 81:340-349. https: //doi.org/10.1017/S0022029914000272.

Lynch, J. M., D. M. Barbano, M. Schweisthal, and J. R. Fleming. 2006. Precalibration evaluation procedures for mid-infrared milk analyzers. J. Dairy Sci. 89:2761-2774. https://doi.org/10.3168/jds .S0022-0302(06)72353-0.

McDermott, A., G. Visentin, M. De Marchi, D. P. Berry, M. A. Fenelon, P. M. O'Connor, O. A. Kenny, and S. McParland. 2016. Prediction of individual milk proteins including free amino acids in bovine milk using mid-infrared spectroscopy and their correlations with milk processing characteristics. J. Dairy Sci. 99:3171-3182. https://doi.org/10.3168/jds.2015-9747.

McParland, S., and D. P. Berry. 2016. The potential of Fourier transform infrared spectroscopy of milk samples to predict energy intake and efficiency in dairy cows. J. Dairy Sci. 99:4056-4070. https://doi.org/10.3168/jds.2015-10051.

McParland, S., E. Kennedy, E. Lewis, S. G. Moore, B. McCarthy, M. O'Donovan, and D. P. Berry. 2015. Genetic parameters of dairy cow energy intake and body energy status predicted using midinfrared spectrometry of milk. J. Dairy Sci. 98:1310-1320. https:/ /doi.org/10.3168/jds.2014-8892.

Mehtiö, T., P. Mäntysaari, T. Kokkonen, S. Kajava, T. Latomäki, L. Nyholm, C. Grelet, T. Pitkänen, E. A. Mäntysaari, and M.
Lidauer. 2018. Developing an indicator for body fat mobilisation using mid-infrared spectrometry of milk samples in dairy cows. Proc. 11th World Congr. Genet. Appl. Livest. Prod., Auckland, New Zealand. WCGALP, Auckland, New Zealand.

Mevik, B. H., R. Wehrens, and K. H. Liland. 2018. pls: Partial Least Squares and Principal Component Regression. R package version 2.7-0. https://CRAN.R-project.org/package=pls.

Schuhmacher, D., B. Bähre, C. Gottschlich, F. Heinemann, and B. Schmitzer. 2017. transport: Optimal Transport in Various Forms. $\mathrm{R}$ package version 0.9-4. https://cran.r-project.org/package= transport.

Shetty, N., P. Løvendahl, M. S. Lund, and A. J. Buitenhuis. 2017. Prediction and validation of residual feed intake and dry matter intake in Danish lactating dairy cows using mid-infrared spectroscopy of milk. J. Dairy Sci. 100:253-264. https://doi.org/10.3168/ jds.2016-11609.

Soyeurt, H., I. Misztal, and N. Gengler. 2010. Genetic variability of milk components based on mid-infrared spectral data. J. Dairy Sci. 93:1722-1728. https://doi.org/10.3168/jds.2009-2614.

Toffanin, V., M. De Marchi, N. Lopez-Villalobos, and M. Cassandro. 2015. Effectiveness of mid-infrared spectroscopy for prediction of the contents of calcium and phosphorus, and titratable acidity of milk and their relationship with milk quality and coagulation properties. Int. Dairy J. 41:68-73. https://doi.org/10.1016/j .idairyj.2014.10.002.

Toledo-Alvarado, H., A. I. Vazquez, G. de los Campos, R. J. Tempelman, G. Bittante, and A. Cecchinato. 2018a. Diagnosing pregnancy status using infrared spectra and milk composition in dairy cows. J. Dairy Sci. 101:2496-2505. https://doi.org/10.3168/jds .2017-13647.

Toledo-Alvarado, H., A. I. Vazquez, G. de los Campos, R. J. Tempelman, G. Gabai, A. Cecchinato, and G. Bittante. 2018b. Changes in milk characteristics and fatty acid profile during the estrous cycle in dairy cows. J. Dairy Sci. 101:9135-9153. https://doi.org/ $10.3168 /$ jds.2018-14480.

Vanlierde, A., F. Dehareng, E. Froidmont, P. Dardenne, P. Kandel, N. Gengler, M.H. Deighton, F. Buckley, E. Lewis, and S. McParland. 2013. Prediction of the individual enteric methane emission of dairy cows from milk mid-infrared spectra. Adv. Anim. Biosci. 4:433.

Vanlierde, A., M. L. Vanrobays, F. Dehareng, E. Froidmont, H. Soyeurt, S. McParland, E. Lewis, M. H. Deighton, F. Grandl, M. Kreuzer, and B. Gredler. 2015. Hot topic: Innovative lactationstage-dependent prediction of methane emissions from milk midinfrared spectra. J. Dairy Sci. 98:5740-5747. https://doi.org/10 $.3168 /$ jds.2014-8436.

Visentin, G., A. McDermott, S. McParland, D. P. Berry, O. A. Kenny, A. Brodkorb, M. A. Fenelon, and M. De Marchi. 2015. Prediction of bovine milk technological traits from mid-infrared spectroscopy analysis in dairy cows. J. Dairy Sci. 98:6620-6629. https://doi.org/ 10.3168/jds.2015-9323.

Wang, Q., and H. Bovenhuis. 2018. Genome-wide association study for milk infrared wavenumbers. J. Dairy Sci. 101:2260-2272. https:// doi.org/10.3168/jds.2017-13457.

Wang, Q., A. Hulzebosch, and H. Bovenhuis. 2016. Genetic and environmental variation in bovine milk infrared spectra. J. Dairy Sci. 99:6793-6803. https://doi.org/10.3168/jds.2015-10488.

Wang, Y., D. J. Veltkamp, and B. R. Kowalsky. 1991. Multivariate instrument standardisation. Anal. Chem. 63:2750-2756. https:// doi.org/10.1021/ac00023a016. 